Lepr Rev (1996) 67, 169-170

\title{
Editorial
}

\section{THE INCOMING EDITOR'S VIEWPOINT}

It is a great privilege to be taking over the editorship of Leprosy Review from Professor J. L. Turk. In the eight years of his editorship he has guided the Journal through some difficult periods while maintaining its position as one of the major English language leprosy journals. One of the pleasures of Leprosy Review is its wide dissemination and it always pleases me to see copies in remote clinics. I am aware that for many people working in remote areas it may be the only specialist journal that they receive. For these reasons Leprosy Review has a wide remit; keeping people abreast of new developments in leprosy, informing readers about leprosy elsewhere as well as discussing management issues. I am keen that the Journal should present the range of research and development from all over the world so keeping readers in touch with developments outside their own areas. I also feel that the Journal should reflect the breadth of research activity in leprosy, from peptides to plantar ulcers.

Continuing education is part of everybody's medical practise and one of the areas that I would like to develop is the educational part of the Journal. We have already started this theme with a series of four wall posters which we hope will be useful to readers in their practice and as educational tools. We are also starting a series of review articles on different aspects of disease management in leprosy. Reader's suggestions on these ideas are most welcome. It would also be helpful to know what topics you would like covered, would a series on prevention of disability be useful? In view of the global flavour of the Journal I would also like to pick up topical issues in contemporary medicine such as evidence-based medicine and how it might be practised in developing countries.

Another suggestion has been that we should have themed issues, perhaps an issue on women and leprosy, these would need to be planned well in advance in order to encourage people to submit data appropriate for such issues.

As the millennium approaches there are new challenges for leprosy workers. The success of multidrug therapy has resulted in declining active caseloads for many workers and there is much debate about how to ensure the best provision of early diagnosis, good management and prevention of disability in leprosy patients. These are complex issues and no single solution will be appropriate the world over. I hope that Leprosy Review will provide a forum for discussion and constructive debate on this important and topical issue with readers sharing their experiences.

One of the paradoxes of medical journals is that the editors ask their readership to be both writers who submit papers and readers who enjoy the journal. In a recent editorial 
Cairns Smith documented the decline in leprosy publications but also highlighted numerous areas that still neded researching ${ }^{1}$. A continuing decline should be averted by leprosy workers responding to these new challenges. I hope that you will all continue to be both readers and writers for Leprosy Review.

Hospital for Tropical Diseases

Diana N. J. Lockwood

4 St Pancras Way

London NW1 OPE

\section{Reference}

${ }^{1}$ Cairns Smith W. Is there a decline in leprosy publications and research? Lepr Rev (1996); 67: 1-3. 